\title{
Effects of active dried Saccharomyces cerevisiae on ruminal fermentation and bacterial community during the short-term ruminal acidosis challenge model in Holstein calves
}

\author{
Yumi Watanabe,${ }^{1 *}$ Yo-Han Kim, ${ }^{1 *}$ Shiro Kushibiki, ${ }^{2}$ Kentaro Ikuta, ${ }^{3}$ Toshihiro Ichijo, ${ }^{1}$ and Shigeru Sato ${ }^{1} \dagger$ \\ ${ }^{1}$ Cooperative Department of Veterinary Medicine, Faculty of Agriculture, Iwate University, Morioka, Iwate 020-8550, Japan \\ ${ }^{2}$ National Institute of Livestock and Grassland Science, Tsukuba, Ibaraki 305-0901, Japan \\ ${ }^{3}$ Awaji Agricultural Technology Center, Minami-Awaji, Hyogo 656-0442, Japan
}

\section{ABSTRACT}

We investigated the effects of active dried Saccharomyces cerevisiae (ADSC) on ruminal $\mathrm{pH}$, fermentation, and the fluid bacterial community during the shortterm ruminal acidosis challenge. Five rumen-fistulated male Holstein calves $(147.0 \pm 5.8 \mathrm{~kg}$ of body weight; $3.6 \pm 0.2 \mathrm{mo}$ of age) were used in a crossover design, and $0 \mathrm{~g}$ (control group, $\mathrm{n}=5$ ) or $2 \mathrm{~g}$ (SC group, $\mathrm{n}=5$ ) of $\operatorname{ADSC}\left(1 \times 10^{10} \mathrm{cfu} / \mathrm{g}\right)$ was administered twice daily for 21 consecutive days. Calves were fed a high-forage diet during the first $15 \mathrm{~d}$ ( $\mathrm{d}-14$ to $\mathrm{d} 0$; prechallenge), a high-grain diet for $2 \mathrm{~d}$ (d 1 and 2; ruminal acidosis challenge), and a high-forage diet for $4 \mathrm{~d}$ (d 3 to 6; postchallenge). Ruminal $\mathrm{pH}$ was measured continuously. Rumen fluid samples were collected once daily $(0800 \mathrm{~h})$ on $\mathrm{d}$ $0,3,4$, and 6 and twice daily (0800 and $1100 \mathrm{~h}$ ) on d 1 and 2. Bacterial DNA was extracted from fluid samples collected on d 0 and 3. The 24-h and 1-h mean ruminal $\mathrm{pH}$ was significantly depressed during the ruminal acidosis challenge in each group, although the changes were more severe in the SC group, consistent with a significant increase in lactic acid on d $2(1100 \mathrm{~h})$ compared with d 0 and a significantly higher proportion of butyric acid on d $2(1100 \mathrm{~h})$ compared with the control group. Feeding a high-grain diet caused a decrease in bacterial diversity due to high acidity in both groups. The relative abundances of the genus Bifidobacterium and operational taxonomic unit (OTU) 3 (Bifidobacterium species) increased significantly in both groups but were higher in the SC group. Correlation analyses indicated that OTU3 (Bifidobacterium species) were positively correlated with lactic acid concentration and

Received October 18, 2018.

Accepted March 8, 2019.

*These authors contributed equally to this work.

$\dagger$ Corresponding author: sshigeru@iwate-u.ac.jp that OTU1 (Prevotella species) and OTU5 (Succinivibrio species) were correlated with the proportion of butyric acid. These results suggest that ADSC supplementation induced the intense decreases in ruminal $\mathrm{pH}$ by increased butyric and lactic acid production through a high-grain diet fermentation by rumen fluid bacterial species during the short-term ruminal acidosis challenge in Holstein calves after weaning.

Key words: rumen fluid bacterial community, Holstein calf, active dried Saccharomyces cerevisiae, ruminal acidosis challenge

\section{INTRODUCTION}

The microbial feed additive Saccharomyces cerevisiae has been administered to improve rumen fermentation and production in dairy cows (AlZahal et al., 2014). Saccharomyces cerevisiae supplementation improves ruminal fermentation, milk production, and starch digestion in cattle (AlZahal et al., 2014; Vyas et al., 2014) as well as DMI and growth performance in neonatal calves (Lesmeister et al., 2004; Xiao et al., 2016). Specifically, AlZahal et al. (2014) reported that active dried S. cerevisiae (ADSC) supplementation alleviated the severity of SARA and improved DMI and FCM yield in lactating dairy cows during 3 wk of feeding a highgrain (HG) diet. In pre- and postweaned dairy calves, S. cerevisiae supplementation significantly reduced the potential pathogenic bacteria genera (Streptococcus and Tyzzerella_4) and pathogenic bacterium (Peptoclostridium) and increased the potential beneficial bacteria (Ruminococcaceae USG 005, Rosburnia, and Olsenella; Fomenky et al., 2018). In addition, feeding S. cerevisiae culture medium enhanced DMI and growth, and fermentation products improved butyrate production and gastrointestinal morphology in neonatal dairy calves (Lesmeister et al., 2004; Xiao et al., 2016).

A short-term SARA challenge following an HG diet induced adverse changes in ruminal $\mathrm{pH}$ and fermenta- 
tion (Khafipour et al., 2009; Li et al., 2012). Ruminal $\mathrm{pH}$ decreases significantly due to increased fermentation products and insufficient rumen buffering, and this may result in depressed food intake, poor body condition, and reduced production (Plaizier et al., 2008). Meanwhile, rumen bacterial communities are continuously changing from birth to adulthood (Jami et al., 2013) and could be significantly affected by the short-term SARA or acidic conditions in the rumen (Hook et al., 2011; Petri et al., 2013). Furthermore, the rumen environment undergoes dramatic changes during the transition from liquid to solid feed consumption in the weaning transition (Kim et al., 2016), and sufficient energy and nutrients are required in postweaned calves to allow optimal growth of the body and rumen as well. Therefore, even if calves reach a substantial BW and appear to develop a rumen microbial community that is similar to that of adult cattle soon after weaning, they may still have immature rumen fermentative ability and thus may not produce satisfactory energy from an HG diet in the rumen. Several studies have reported that various types of $S$. cerevisiae supplementation can improve health, performance, and rumen fermentation in dairy calves before weaning (Lesmeister et al., 2004; Xiao et al., 2016), and ADSC supplementation may support maintenance of stable fermentation in the rumen when SARA is induced through abrupt dietary change from a high-forage (HF) diet to an HG diet (Thrune et al., 2009; AlZahal et al., 2014; Vyas et al., 2014).

The effect of yeast supplementation on rumen fermentation and the bacterial community in Holstein calves after weaning has not been studied extensively. Therefore, we investigated the effects of ADSC supplementation on ruminal $\mathrm{pH}$, fermentation, and the bacterial community in rumen fluid during the shortterm ruminal acidosis challenge in Holstein calves. We hypothesized that ADSC supplementation may alleviate the adverse changes in ruminal $\mathrm{pH}$, fermentation kinetics, and the bacterial community that typically occur during the ruminal acidosis challenge and thus may play a supportive role in the growth performance of Holstein calves.

\section{MATERIALS AND METHODS}

\section{Animals and Experimental Design}

All animals were cared for according to protocols approved by the Iwate University Laboratory Animal Care and Use Committee (A201453; Morioka, Japan). Five male Holstein calves $(147.0 \pm 5.8 \mathrm{~kg}$ of BW; 3.6 $\pm 0.2 \mathrm{mo}$ of age) equipped with rumen fistula at $4 \mathrm{wk}$
Table 1. Composition and chemical analysis of the experimental diets

\begin{tabular}{lrrr}
\hline Item & Forage & $\begin{array}{c}\text { High } \\
\text { forage }\end{array}$ & $\begin{array}{c}\text { High } \\
\text { grain }\end{array}$ \\
\hline Amount (\%) & & & \\
$\quad$ Orchard and timothy hay & 100 & 57 & 0 \\
Concentrate & 0 & 43 & 50 \\
$\quad$ Soybean flakes & 0 & 0 & 50 \\
DM basis (\%) & & & \\
TDN & 60.9 & 68.4 & 80.5 \\
CP & 13.0 & 15.2 & 15.7 \\
ADF & 40.5 & 30.7 & 12.8 \\
NDF & 68.0 & 51.3 & 25.7 \\
NFC & 8.1 & 20.8 & 48.7 \\
Ca & 0.5 & 0.6 & 0.4 \\
P & 0.3 & 0.3 & 0.4 \\
\hline
\end{tabular}

${ }^{1}$ Calculated value.

${ }^{2} \mathrm{NFC}$ calculated as $(100$ - crude fat - CP - NDF - ash).

of age (about 3 mo before the experiment) were housed individually in $2.0-\times 1.2-\mathrm{m}$ pens with rubber mats with free access to water throughout the study period. A crossover design (experimental periods 1 and 2) with a 2 -wk wash-out period ( $100 \%$ forage diet feeding ad libitum) was used, and $0 \mathrm{~g}$ (control group, $\mathrm{n}=5$ ) or 2 g (SC group, $\mathrm{n}=5$ ) of gelatin-encapsulated Levucell SC containing $1 \times 10^{10} \mathrm{cfu} / \mathrm{g}$ of ADSC strain CNCM I-1077 (Lallemand, Toulouse, France) was administered twice daily (0800 and $1700 \mathrm{~h}$ ) through the rumen fistula for 21 consecutive days (d -14 to 6$)$. Unchopped hay and concentrate diets (HF diet) were fed to calves during the first $15 \mathrm{~d}$ (prechallenge; $\mathrm{d}-14$ to 0 ), HG diet for $2 \mathrm{~d}$ (ruminal acidosis challenge; $\mathrm{d} 1$ and 2 ), and $\mathrm{HF}$ diet for $4 \mathrm{~d}$ (postchallenge; $\mathrm{d} 3$ to 6 ). The ruminal acidosis challenge was defined as an HF diet followed by an HG diet. Feed was supplied daily in 2 equal portions at 0800 and $1700 \mathrm{~h}$, and it was confirmed that all feeds offered to calves were consumed. The chemical compositions of the forage, HF, and HG diets fed to the calves are shown in Table 1. No antibiotics were used before or during the experiment period except at the time of rumen fistulation surgery (4 wk of age).

\section{Sampling and Measurements}

Ruminal $\mathrm{pH}$ was measured continuously every 10 min throughout the experimental period using a radio transmission system (YCOW-S; DKK-TOA, Yamagata, Japan) as previously described (Sato et al., 2012). A $\mathrm{pH}$ sensor was placed into the ventral sac of the rumen through the rumen fistula. The location of the $\mathrm{pH}$ sensor in the rumen was confirmed every morning by palpation through the rumen fistula, and the sensor remained at the ventral sac and ruminal mat throughout the experiment periods. Calibration was performed 
using standards at $\mathrm{pH} 4$ to 7 (DKK-TOA) before, during (every $2 \mathrm{wk}$ ), and after the experiment, and no drift in $\mathrm{pH}$ was observed in measurements taken during the experimental period. Rumen fluid samples were collected once daily $(0800 \mathrm{~h})$ on d $0,3,4$, and 6 (pre- and postchallenge) and twice daily (0800 and $1100 \mathrm{~h}$ ) on d 1 and 2 (ruminal acidosis challenge) for analyses of the bacterial community, total VFA concentration, the proportions of individual VFA, $\mathrm{NH}_{3}-\mathrm{N}$ levels, and lactic acid concentrations. The collected samples were immediately filtered through 2 layers of cheesecloth and stored at $-80^{\circ} \mathrm{C}$ until usage.

For VFA analyses, $1 \mathrm{~mL}$ of $25 \% \mathrm{HO}_{3} \mathrm{P}$ in $3 \mathrm{~N} \mathrm{H}_{2} \mathrm{SO}_{4}$ was added to $5 \mathrm{~mL}$ of rumen fluid. Total VFA and component VFA (i.e., acetic acid, propionic acid, and butyric acid) were separated and quantified through GC (model 135, Hitachi, Tokyo, Japan) using a packed glass column (Thermon-3000, 3\%) with a Shimalite TPA 60-80 mesh support (Shinwa Chemical Industries Ltd., Kyoto, Japan). For lactic acid analyses, fluid samples were centrifuged at $2,000 \times g$ for 15 min at $4^{\circ} \mathrm{C}$, and the concentration of lactic acid in the supernatant was determined using a commercially available kit (F-kit; D-lactate/L-lactate, J. K. International Co., Tokyo, Japan). To measure the $\mathrm{NH}_{3}-\mathrm{N}$ concentration, fluid samples were analyzed using the steam distillation method with an $\mathrm{NH}_{3}-\mathrm{N}$ analyzer (Kjeltec Auto Sampler System 1035 Analyzer, Tecator Inc., Höganäs, Sweden). To measure ruminal LPS activity, rumen fluid samples were centrifuged at $11,000 \times g$ for $15 \mathrm{~min}$ at $4^{\circ} \mathrm{C}$ and assayed using a kinetic Limulus amebocyte lysate assay (Pyrochrome with Glucashield, Seikagaku Corp., Tokyo, Japan). The detailed procedures for sample preparation and method validation have been described elsewhere (Hirabayashi et al., 2017).

\section{DNA Isolation}

Total bacterial DNA was extracted from rumen fluid samples collected on d 0 and 3 for 454 pyrosequencing analyses as previously described (Kim et al., 2016). Briefly, samples were incubated with $750 \mu \mathrm{g} / \mathrm{mL}$ lysozyme (Sigma-Aldrich Co., St. Louis, MO) at $37^{\circ} \mathrm{C}$ for $90 \mathrm{~min}$. This was followed by adding $10 \mu \mathrm{L}$ of purified achromopeptidase (Wako Pure Chemical Industries Ltd., Osaka, Japan) at a concentration of 10,000 U/ $\mathrm{mL}$, and the resulting mixture was incubated at $37^{\circ} \mathrm{C}$ for $30 \mathrm{~min}$. This suspension was treated with $60 \mu \mathrm{L}$ of $1 \% \mathrm{SDS}$ and $1 \mathrm{mg} / \mathrm{mL}$ proteinase $\mathrm{K}$ (Merck Japan Ltd., Tokyo, Japan) and incubated at $55^{\circ} \mathrm{C}$ for $5 \mathrm{~min}$. Then, the lysate was treated with phenol/chloroform/ isoamyl alcohol (Wako Pure Chemical Industries Ltd.) and chloroform (Life Technologies Japan Ltd., Tokyo, Japan). The DNA was precipitated with $5 \mathrm{M} \mathrm{NaCl}$ and $100 \%$ ethanol, followed by centrifugation at 21,900 $\times g$ for 15 min at $4^{\circ} \mathrm{C}$. The DNA pellet was rinsed with $70 \%$ ethanol, dried, and dissolved in Tris-hydrochloride buffer. Purified DNA was quantified using a Biospec-Nano spectrophotometer (Shimadzu Biotech, Kyoto, Japan) and was stored at $-80^{\circ} \mathrm{C}$ until further analyses.

\section{DNA Pyrosequencing}

The V1/V2 region of the $16 \mathrm{~S}$ rRNA gene was amplified using a forward primer (5'-CCATCTCATCCCTGCGTGTCTCCGACTCAGNNNNNNNNNNAGRGTTTGATYMTGGCTCAG-3') containing 454 primer A, a 10-bp barcode sequence unique for each sample (indicated by N), and 27Fmod (5'-AGRGTTTGATYMTGGCTCAG), in which the third base, A, in the original primer $27 \mathrm{~F}$ had been changed to $\mathrm{R}$. The reverse primer (5'-CCTATCCCCTGTGTGCCTTGGCAGTCTCAGTGCTGCCTCCCGTAGGAGT-3') contained 454 primer $\mathrm{B}$ and the reverse primer $338 \mathrm{R}$ (5'-TGCTGCCTCCCGTAGGAGT). Amplified products (approximately $370 \mathrm{bp}$ ) were confirmed using agarose gel electrophoresis. Then, they were purified using AMPureXP magnetic purification beads (Beckman Coulter Inc., Brea, CA) and quantified using the Quant-iT PicoGreen dsDNA assay kit (Life Technologies Japan Ltd.). Mixed samples were prepared by pooling approximately equal amounts of PCR amplicons from each sample, which were subjected to 454 GS Junior (Roche Applied Science, Indianapolis, IN) sequencing, following the manufacturer's instructions. The sequence data were deposited into the Sequence Read Archive of the National Center for Biotechnology Information and can be accessed via accession number SRP092363 (https:// submit.ncbi.nlm.nih.gov/subs/sra/).

\section{Pyrosequencing Data Analyses}

All pyrosequencing reads were filtered according to the procedures outlined by Kim et al. (2013), who developed an analysis pipeline for barcoded 454 pyrosequencing of 27Fmod/338R-amplified PCR products in the V1/V2 region. Pyrosequencing reads were assigned to each sample based on the barcode sequence information. Any resulting sequences that did not have PCR primer sequences at both sequence termini or that had average quality values $>25$ were filtered out. Chimeras with $>90 \%$ similarity to reference sequences in the database, as determined using BLAST (https://blast.ncbi .nlm.nih.gov/Blast.cgi), were removed. Finally, filtered 
reads were obtained for further analyses by trimming off both primer sequences.

A total of 238,464 filtered sequences were obtained from the analysis pipeline (Kim et al., 2013), and these reads were further processed using the Mothur program (version 1.39.5, University of Michigan; http: //www.mothur.org/wiki/; Schloss et al., 2009) following the 454 standard operating procedure (http:// www.mothur.org/wiki/454_SOP; Schloss et al., 2011) with minor modifications. To obtain a nonredundant set of sequences, unique sequences were identified and were used for alignment against the SILVA reference database (SSURef release 128; Pruesse et al., 2007). Then, candidate sequences were screened and filtered; unique sequences were determined; candidate sequences were preclustered to eliminate outliers; chimeras were removed using the chimera.uchime program (http:// drive5.com/uchime); sequence comparisons were carried out using the Mothur Ribosomal Database Project tools training set, version 16; sequences identified as being of eukaryotic origin were removed; and, finally, a distance matrix was generated from the resulting sequences. Sequences were clustered and classified into operational taxonomic units (OTU) with a cutoff value of $97 \%$ similarity. Representative sequences for each OTU were assigned using the "get.oturep" command, and sequence comparisons were carried out using the BLASTn program (https://blast.ncbi.nlm.nih .gov/Blast.cgi) against a reference genome database constructed from genomic sequences found in GenBank (ftp://ftp.ncbi.nlm.nih.gov/blast/db/). The maximum observed rarefaction OTU values and rarefaction curves for each group were determined using the "rarefaction. single" command at a 97\% similarity level. All samples were standardized with random subsampling (868 sequences/sample) using the "sub.sample" command, and the "summary.single" command was used to calculate Good's coverage, Chao1, abundance-based coverage estimator, and Shannon diversity index. The unweighted UniFrac distance method (Lozupone and Knight, 2005) was used to perform principal coordinates analyses (PCoA) with all OTU.

\section{Quantitative Real-Time PCR}

Quantitative real-time PCR (qPCR) of bacterial species in the rumen fluid was performed, as described previously (Kim et al., 2016), to evaluate the 16S rRNA genes of the major bacterial species in the rumen: total bacteria, Fibrobacter succinogenes, Megasphaera elsdenii, Ruminococcus albus, and Ruminococcus flavefaciens. Primer pairs for total bacteria and each bacterial species are shown in Supplemental Table S1 (https:/ /doi.org/10.3168/jds.2018-15871). The strains used for plasmid preparation were as follows: F. succinogenes ATCC19169, M. elsdenii ATCC25940, R. albus ATCC27210, and R. flavefaciens ATCC19208.

\section{Blood Sampling and Plasma Metabolite Profiles}

Blood samples were collected once daily (0800 h) on d $0,3,4$, and 6 (pre- and postchallenge) and twice daily (0800 and $1100 \mathrm{~h}$ ) on d 1 and 2 (ruminal acidosis challenge) from the jugular vein into $10-\mathrm{mL}$ evacuated serum-separating tubes and tubes containing sodium fluoride (BD Vacutainer, Franklin Lakes, NJ) at the same time as rumen fluid sample collection. The samples were immediately centrifuged $(1,500 \times g, 15 \mathrm{~min}$, $\left.4^{\circ} \mathrm{C}\right)$ to separate the serum and preserved at $-80^{\circ} \mathrm{C}$ until analyses. Glucose, free fatty acid, BHB, total cholesterol, BUN, albumin, aspartate transaminase, and $\gamma$-glutamyl transpeptidase were measured using an automated biochemistry analyzer (Accute, Toshiba Ltd., Tokyo, Japan).

\section{Statistical Analyses}

The 24-h mean ruminal $\mathrm{pH}$ data were categorized as duration of time when $\mathrm{pH}$ was $<5.6$ and area under $\mathrm{pH}$ 5.6. Total VFA, $\mathrm{NH}_{3}-\mathrm{N}$, and lactic acid concentrations, proportions of individual VFA, and ruminal ratios of acetic acid to propionic acid were summarized once daily $(0800 \mathrm{~h})$ on d $0,3,4$, and 6 and twice daily (0800 and $1100 \mathrm{~h}$ ) on $\mathrm{d} 1$ and 2 . The relative abundances of bacterial phyla, genera, and OTU as well as indices of bacterial diversity were summarized on d 0 and $3(0800$ h). Significant differences between the control and SC groups at the same time points were evaluated using the Mann-Whitney U test. One-way repeated-measures ANOVA, followed by Tukey's multiple comparison method, was used to determine within-group differences between d 0 and other days. Pearson correlation coefficient $(\mathrm{r})$ and significance level ( $P$-value) in the control and SC groups were used to determine the relationships among rumen parameters (24-h mean ruminal $\mathrm{pH}$, time with $\mathrm{pH}$ under 5.6, area under $\mathrm{pH} 5.6$, total VFA and lactic acid concentrations, proportions of individual VFA, and LPS activity) and OTU. A heatmap was constructed using the gplots package in $\mathrm{R}$ version 3.3.2 (http://www.r-project.org; R Foundation for Statistical Computing, Vienna, Austria) with Pearson correlation data. Carryover effect was determined between experimental periods 1 and 2 by unpaired Student's $t$-test. All numerical data were analyzed using Prism version 7.01 (GraphPad Software Inc., La Jolla, CA). Significant differences were determined with a threshold of $P$ 
$<0.05$, and trends that suggested possible significance were identified at $P<0.10$.

\section{RESULTS}

\section{Growth Performance, Ruminal pH, and VFA}

No significant difference $(P>0.1)$ in BW gain was observed between experimental periods 1 and 2 (17.1 \pm 0.9 vs. $15.0 \pm 2.2 \mathrm{~kg}$ of $\mathrm{BW}$ gain, respectively) or between the control and SC groups $(17.1 \pm 0.8$ vs. 15.0 $\pm 2.3 \mathrm{~kg}$ of BW gain, respectively). The $24-\mathrm{h}$ and $1-\mathrm{h}$ mean ruminal $\mathrm{pH}$ values were dramatically depressed in both groups during the ruminal acidosis challenge, although the changes were more severe in the $\mathrm{SC}$ group (Table 2; Figure 1). The 24-h mean ruminal $\mathrm{pH}$ of the control and SC groups had similar levels (6.19 vs. 6.20 , respectively) during the prechallenge observation (d 0). However, the 24-h mean ruminal $\mathrm{pH}$ on $\mathrm{d}$ 2 tended to decrease $(P=0.095)$ in the control group and decreased $(P<0.05)$ in the SC group compared with those on d 0. Furthermore, the SC group tended to have lower $(P=0.095) 24$-h mean ruminal $\mathrm{pH}$ on d 2 compared with the control group. The 1-h mean ruminal $\mathrm{pH}$ also exhibited large fluctuations during the ruminal acidosis challenge. Specifically, the SC group had lower $(P<0.05)$ 1-h mean ruminal $\mathrm{pH}$ values on $\mathrm{d} 2$ at 1300 and $1400 \mathrm{~h}$ (5 and $6 \mathrm{~h}$ after the morning feeding, respectively) compared with the control group (Figure 1). In accordance with the changes in ruminal $\mathrm{pH}$, the duration of time when ruminal $\mathrm{pH}$ was under 5.6 and 5.8, as well as the area under ruminal $\mathrm{pH} 5.6$ and 5.8, also increased $(P<0.05)$ in both groups on $\mathrm{d}$ 2 and 3 compared with d 0 (Table 2 ).

Total VFA concentration and proportions of individual VFA of the control and SC groups showed similar changes during the ruminal acidosis challenge (Table 3 ). In both groups, total VFA concentration increased $(P<0.05)$ on $\mathrm{d} 1(1100 \mathrm{~h})$ and $\mathrm{d} 2(1100 \mathrm{~h})$; the proportion of acetic acid decreased $(P<0.05)$ on $\mathrm{d} 1(1100$ h), d $2(0800$ and $1100 \mathrm{~h}), \mathrm{d} 3$, and d 4; the proportion of propionic acid increased $(P<0.05)$ on d $2(0800$ and $1100 \mathrm{~h}), \mathrm{d} 3$, and $\mathrm{d} 4$; and the proportion of butyric acid increased $(P<0.05)$ on $\mathrm{d} 1(1100 \mathrm{~h})$ and $\mathrm{d} 2(1100$ h) compared with d 0. Ruminal LPS activity increased $(P<0.05)$ on $\mathrm{d} 3$ in the control group and on $\mathrm{d} 3$ and 4 in the SC group compared with d 0. By contrast, lactic acid concentration increased $(P<0.05)$ only in the SC group on d $2(1100 \mathrm{~h})$ compared with d 0 , and a higher $(P<0.05)$ proportion of butyric acid was identified on d $2(1100 \mathrm{~h})$ in the SC group compared with the control group. The proportion of butyric acid was significant $(P<0.01)$ for carryover effect between periods 1 and 2 (12.4 and $11.2 \%$, respectively).

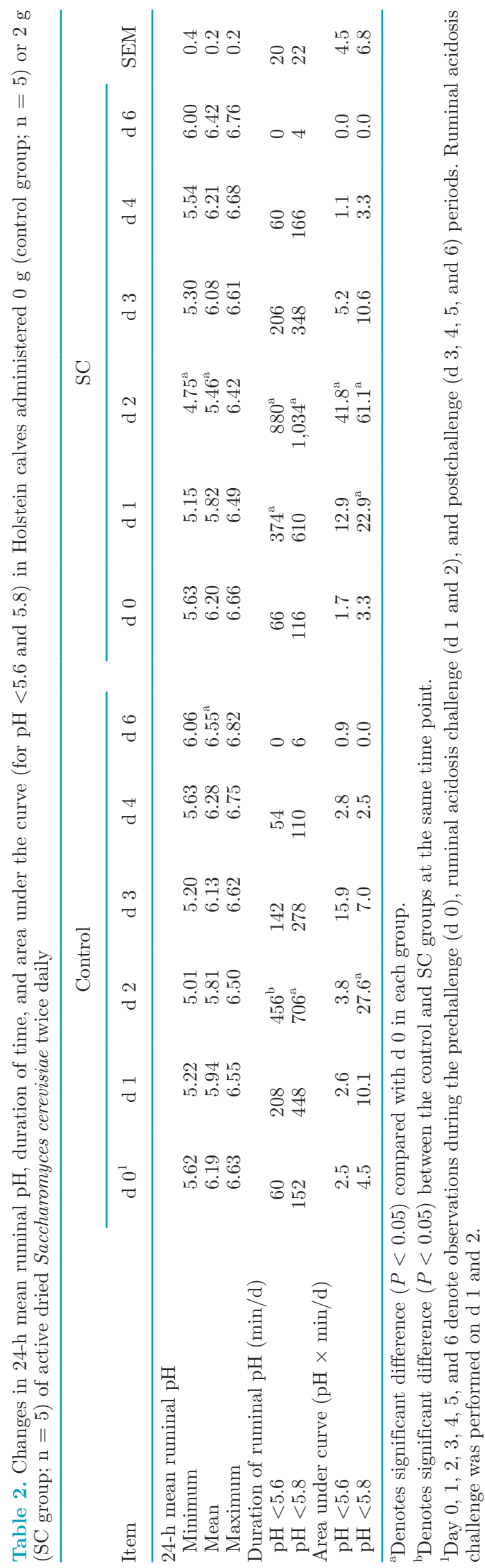

Journal of Dairy Science Vol. 102 No. 7, 2019 


\section{Bacterial Diversity}

Bacterial diversity of the rumen fluid was affected $(P<0.05)$ by the ruminal acidosis challenge in both groups, but these changes were more extreme in the SC group (Table 4), similar to the changes observed in ruminal $\mathrm{pH}$. In both groups, bacterial diversity indices such as OTU number, abundance-based coverage estimator, Chao1, and Shannon index decreased $(P<0.05)$, whereas the Simpson index increased $(P<0.05)$ during the ruminal acidosis challenge. In addition, PCoA plots showed a separation between the prechallenge (d 0) and postchallenge (d 3) periods in both groups, but no notable separation was identified between the 2 groups (principal components $1+2=44 \%$; Figure 2). The maximum observed OTU rarefaction curves for the ruminal bacterial community indicated that bacterial diversity was depressed by the ruminal acidosis challenge in both groups (Supplemental Figure S1, https:/ /doi.org/10.3168/jds.2018-15871). The average Good's coverage was $82.9 \pm 0.0 \%$ (mean $\pm \mathrm{SE}$ ) in the present study.

\section{Bacterial Abundance}

Bacterial composition of the rumen fluid was also affected $(P<0.05)$ by the ruminal acidosis challenge in both groups (Figure 3). At the phylum level, the relative abundance of Firmicutes decreased $(P<0.05)$ in the control group, whereas the relative abundance of Bacteroidetes tended to increase $(P=0.056)$ in the same group during the ruminal acidosis challenge (Table 5). The relative abundance of Actinobacteria increased $(P<0.05)$ in both groups during the ruminal acidosis challenge and tended to be higher $(P=0.095)$ on $\mathrm{d} 3$ in the SC group compared with the control group (Table 5).

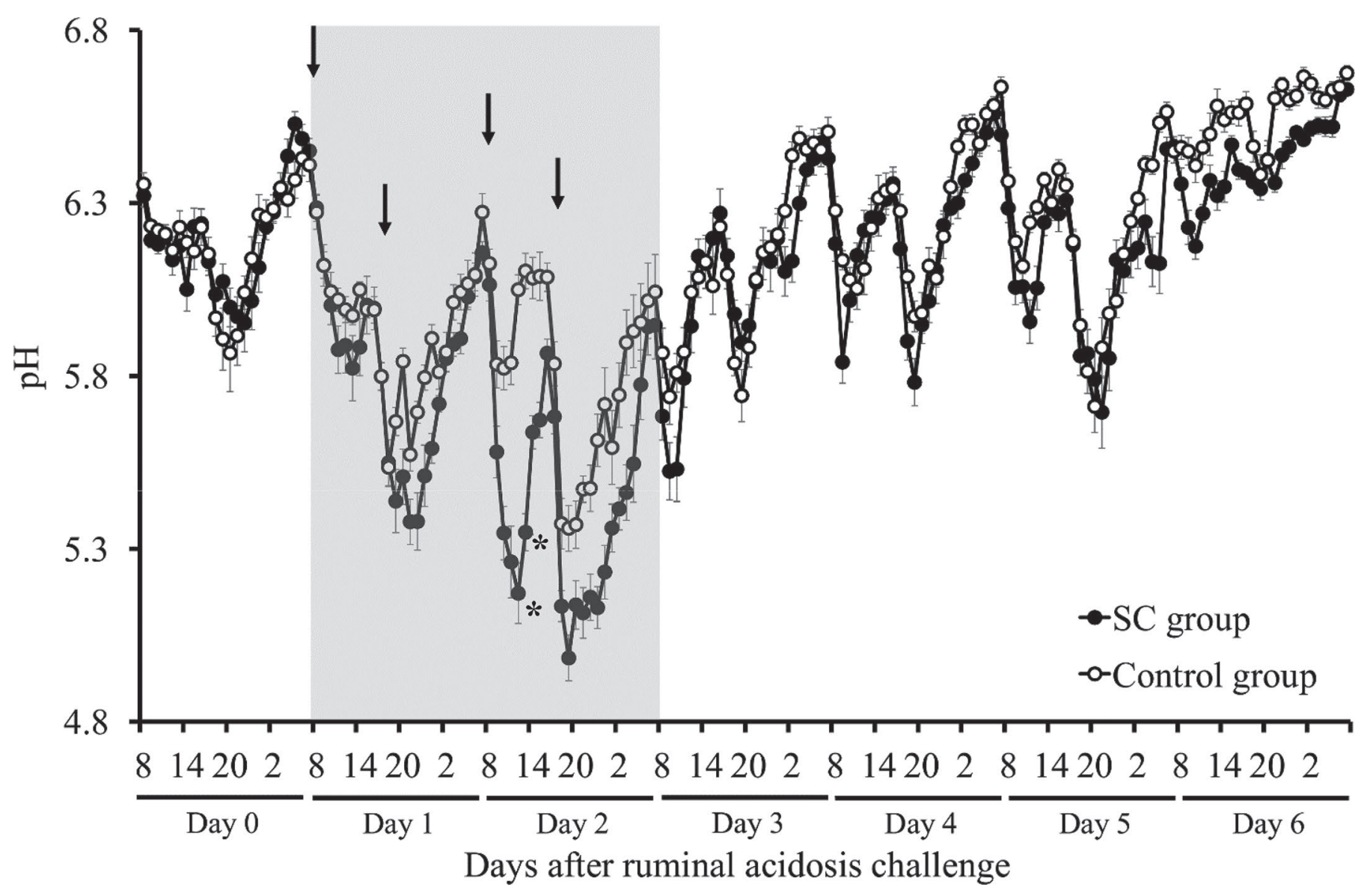

Figure 1. Diurnal changes in the 1-h mean ruminal $\mathrm{pH}$ in Holstein calves administered $0 \mathrm{~g}$ (control group, $\mathrm{n}=5$ ) or $2 \mathrm{~g}(\mathrm{SC}$ group, $\mathrm{n}=$ 5) of active dried Saccharomyces cerevisiae twice daily. Days 0,1,2,3,4,5, and 6 denote observations during the prechallenge (d 0), ruminal acidosis challenge ( $\mathrm{d} 1$ and 2), and postchallenge (d 3, 4, 5, and 6) periods, respectively. The ruminal acidosis challenge was performed on $\mathrm{d} 1$ and 2 (gray square). Arrows indicate feeding of a high-grain diet $(0800$ and $1630 \mathrm{~h})$. ${ }^{*}$ Denotes a significant difference $(P<0.05)$ between the control and SC groups at that time point. Values represent mean $\pm \mathrm{SE}$. 




At the genus level, Prevotella was the most abundant (\% of total sequence) in both groups (Table 5); its proportion increased $(P<0.05)$ only in the control group during the ruminal acidosis challenge and was higher $(P<0.05)$ on $\mathrm{d} 3$ in that group compared with the SC group. The relative abundance of Bifidobacterium increased $(P<0.05)$ in both groups during the ruminal acidosis challenge, whereas the proportion of this genus tended to be higher $(P=0.095)$ on $\mathrm{d} 3$ in the SC group than in the control group. The relative abundances of unclassified Lachnospiraceae, Ruminococcus, and Pseudobutyrivibrio decreased $(P<0.05)$ in both groups during the ruminal acidosis challenge. The relative abundance of unclassified Prevotellaceae in the control group and the relative abundances of unclassified members of Ruminococcaceae, Clostridiales, and Bacteroidetes decreased $(P<0.05)$ in the $\mathrm{SC}$ group during the ruminal acidosis challenge.

At the OTU level, representative sequences for each OTU ( $>0.5 \%$ of total sequences) were assigned to bacterial species based on the BLASTn program (https: //blast.ncbi.nlm.nih.gov/Blast.cgi), queried against a reference genome database constructed from genomic sequences obtained from GenBank (ftp://ftp.ncbi.nlm .nih.gov/blast/db; Table 6). The relative abundance of OTU3 (Bifidobacterium species) increased $(P<0.05)$, whereas OTU8 (Eisenbergiella species), OTU14 (Pseudobutyrivibrio species), and OTU25 (Prevotella species) decreased $(P<0.05)$ in both groups during the ruminal acidosis challenge (Table 6 ). In the SC group, the relative abundances of OTU1 (Prevotella species), OTU13 (Prevotella species), OTU21 (Eisenbergiella species), and OTU27 (Bifidobacterium species) increased $(P<$ 0.05 ), and the relative abundances of OTU16 (Bacteroides species), OTU26 (Clostridium species), and OTU29 (Bacteroides species) decreased $(P<0.05)$ during the ruminal acidosis challenge.

\section{Pearson Correlation Analyses of OTU}

Analyses of Pearson correlation coefficients in the control and SC groups were performed between rumen fermentation parameters (24-h mean ruminal $\mathrm{pH}$; duration of time when the $\mathrm{pH}$ was under 5.6; area under $\mathrm{pH}$ 5.6; total VFA, lactic acid, and $\mathrm{NH}_{3}-\mathrm{N}$ concentrations; and proportions of individual VFA and LPS activity) and OTU ( $>0.5 \%$ of total sequences; Figure 4$)$. Among the OTU that were correlated $(P<0.05)$ with rumen fermentation parameters, the relative abundance of OTU15 (Prevotella species) was negatively $(\mathrm{r}=-0.505$, $P<0.05)$ correlated with the 24 -h mean ruminal $\mathrm{pH}$ and showed positive correlations with the amount of time with $\mathrm{pH}$ under $5.6(\mathrm{r}=0.694, P<0.05)$ and the area under $\mathrm{pH} 5.6(\mathrm{r}=0.625, P<0.05)$. The propor- 
tion of butyric acid was negatively $(\mathrm{r}=-0.462, P<$ $0.05)$ correlated with the relative abundance of OTU3 (Bifidobacterium species) and positively correlated with the relative abundances of OTU1 (Prevotella species; $\mathrm{r}$ $=0.499, P<0.05$ ) and OTU9 (Succinivibrio species; $\mathrm{r}=0.488, P<0.05)$. The lactic acid concentration showed a positive correlation with OTU3 (Bifidobacterium species; $\mathrm{r}=0.699, P<0.05)$ and a negative correlation with OTU25 (Prevotella species; $\mathrm{r}=-0.471$, $P<0.05)$.

\section{S rRNA Copy Number in Rumen Fluid}

The directions of the changes in relative abundance of bacterial copy numbers determined through qPCR analyses were consistent with those of OTU determined through 454 pyrosequencing analyses (Supplemental Figure S2, https://doi.org/10.3168/jds.2018-15871). The relative abundances of $F$. succinogenes, $R$. albus, and $R$. flavefaciens decreased $(P<0.05)$ in the control group, whereas the relative abundances of $R$. albus and $R$. flavefaciens decreased $(P<0.05)$ in both groups during the ruminal acidosis challenge. The relative abundance of $R$. flavefaciens on d 0 tended to be higher $(P=0.095)$ and the relative abundances of $R$. albus and $R$. flavefaciens on $\mathrm{d} 2$ were higher $(P<0.05)$ in the control group than in the SC group.

\section{Blood Metabolite Profiles}

The glucose levels in peripheral blood increased $(P$ $<0.05)$ on d $2(0800 \mathrm{~h}), \mathrm{d} 3$, and $\mathrm{d} 4$ in the control group and on $\mathrm{d} 2(0800 \mathrm{~h})$ and $\mathrm{d} 3$ in the $\mathrm{SC}$ group compared with d 0 (Supplemental Table S1, https:// doi.org/10.3168/jds.2018-15871), whereas there was a significant $(P<0.05)$ carryover effect on glucose concentration between periods 1 and $2(94.3$ and $98.1 \mathrm{mg} /$ $\mathrm{dL}$, respectively). The BHB level increased $(P<0.05)$ on $\mathrm{d} 1(1100 \mathrm{~h})$ in the control group and on $\mathrm{d} 1(1100$

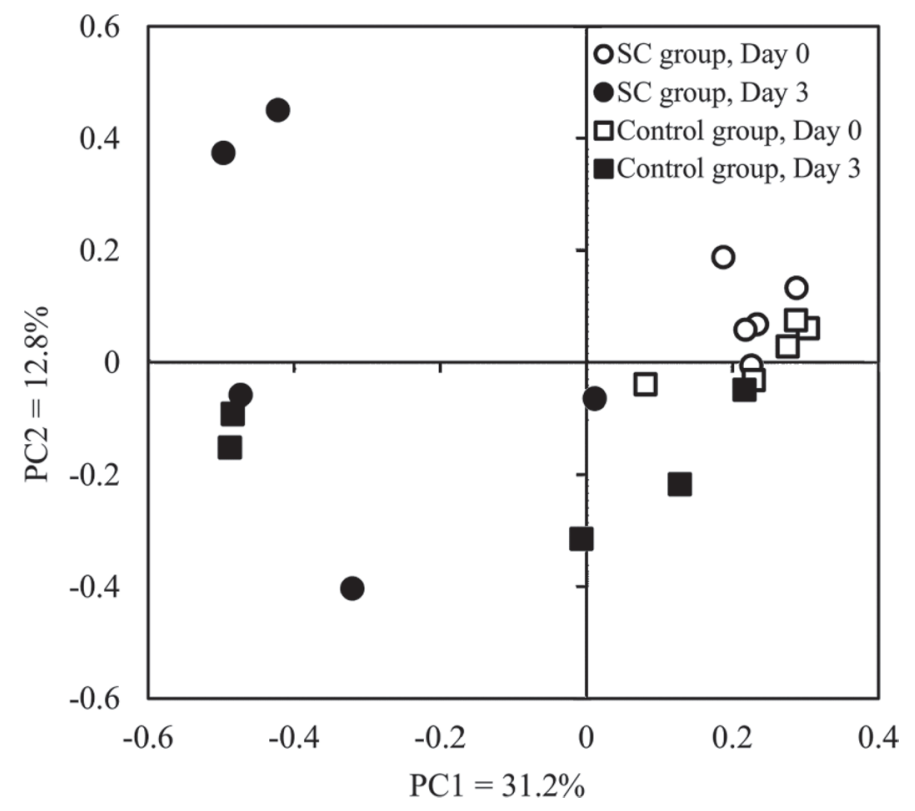

Figure 2. Principal coordinate analysis plots of Holstein calves administered $0 \mathrm{~g}$ (control group, $\mathrm{n}=5$ ) or $2 \mathrm{~g}$ ( $\mathrm{SC}$ group, $\mathrm{n}=5$ ) of active dried Saccharomyces cerevisiae twice daily. Days 0 and 3 denote observations taken $1 \mathrm{~d}$ before and $1 \mathrm{~d}$ after the ruminal acidosis challenge, respectively. The ruminal acidosis challenge was performed on $\mathrm{d} 1$ and 2. $\mathrm{PC} 1$ and $\mathrm{PC} 2$ represent principal components 1 and 2, respectively.

h) and $\mathrm{d} 2(1100 \mathrm{~h})$ in the SC group compared with $\mathrm{d} 0$, and the BHB level on d $2(1100 \mathrm{~h})$ tended to be higher $(P=0.056)$ in the $\mathrm{SC}$ group compared with the control group. The total cholesterol level in the SC group decreased $(P<0.05)$ on $\mathrm{d} 3,4$, and 6 , and the BUN levels in both groups decreased $(P<0.05)$ on $\mathrm{d} 2$ (0800 and $1100 \mathrm{~h}$ ) and $\mathrm{d} 3$ compared with $\mathrm{d} 0$.

\section{DISCUSSION}

It has previously been reported that a short-term SARA challenge following feeding of an HG diet in dairy cows may depress ruminal $\mathrm{pH}$ due to an increase

Table 4. Bacterial diversity indices calculated from 454 pyrosequencing data at the $97 \%$ similarity level in Holstein calves administered $0 \mathrm{~g}$ (control group; $\mathrm{n}=5$ ) or $2 \mathrm{~g}$ (SC group; $\mathrm{n}=5$ ) of active dried Saccharomyces cerevisiae twice daily

\begin{tabular}{lcccccc}
\hline & \multicolumn{3}{c}{ Control } & & \multicolumn{3}{c}{ SC } & \\
\cline { 2 - 3 } \cline { 5 - 6 } Item $^{1}$ & $\mathrm{~d} 0^{2}$ & $\mathrm{~d} 3$ & & $\mathrm{~d} 0$ & $\mathrm{~d} 3$ & SEM \\
\hline OTU & 311 & $170^{\mathrm{a}}$ & & 312 & $108^{\mathrm{a}}$ & 20 \\
ACE & 1,320 & $802^{\mathrm{a}}$ & & 1,280 & $489^{\mathrm{a}}$ & 113 \\
Chao1 & 783 & $441^{\mathrm{a}}$ & & 777 & $281^{\mathrm{a}}$ & 55 \\
Shannon & 4.88 & $3.58^{\mathrm{a}}$ & & 4.91 & $2.62^{\mathrm{a}}$ & 0.25 \\
Simpson & 0.022 & $0.086^{\mathrm{a}}$ & & 0.019 & $0.229^{\mathrm{a}}$ & 0.029 \\
\hline
\end{tabular}

${ }^{a}$ Denotes significant difference $(P<0.05)$ between $\mathrm{d} 0$ and 3 in each group.

${ }^{1} \mathrm{OTU}=$ operational taxonomic unit; $\mathrm{ACE}=$ abundance-based coverage estimator.

${ }^{2}$ Days 0 and 3 denote samples taken $1 \mathrm{~d}$ before and $1 \mathrm{~d}$ after the ruminal acidosis challenge, respectively. Ruminal acidosis challenge was performed on $\mathrm{d} 1$ and 2. 
in fermentation products (Khafipour et al., 2009; Li et al., 2012). Furthermore, calves experience dramatic changes in the rumen environment during the weaning transition and may be unable to produce sufficient energy for growth from an HG diet due to their easily imbalanced rumen microbial community shortly after weaning. In addition, the active dried type of $S$. cerevi- siae has the advantage of a high concentration of viable cells compared with other types (Chaucheyras-Durand et al., 2008), which may maximize the effects of $S$. cerevisiae supplementation. Therefore, we hypothesized that ADSC supplementation of Holstein calves can support rumen fermentation and the fluid bacterial community during short-term ruminal acidosis challenge.
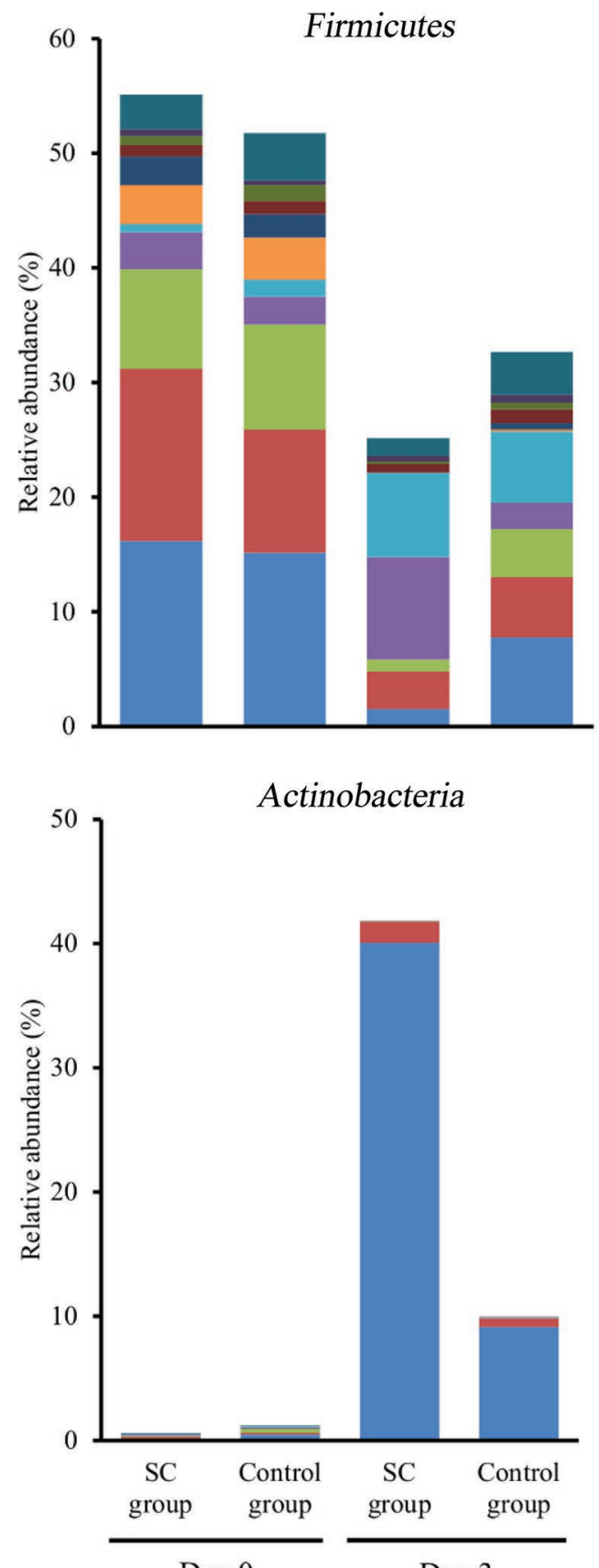

Day 0
@ Others

-unclassified

Veillonellaceae

nunclassified

Firmicutes

- Succiniclasticum

- Pseudobutyrivibrio

Ruminococcus

- Sharpea

- Kandleria

unclassified

Clostridiales

unclassified

Lachnospiraceae

- unclassified

Ruminococcaceae

athers

unclassified

Bifidobacteriaceae

- unclassified

Actinomycetales

- Pseudoscardovia

- Curtobacterium

unclassified

Actinomycetaceae

- Corynebacterium

unclassified

Coriobacteriaceae

- Trueperella

- Olsenella

- Bifidobacterium

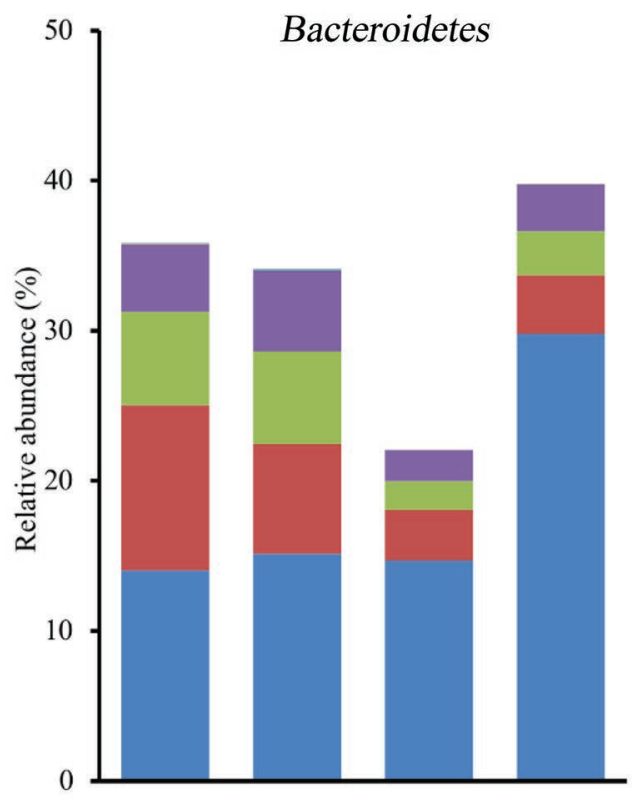

Proteobacteria

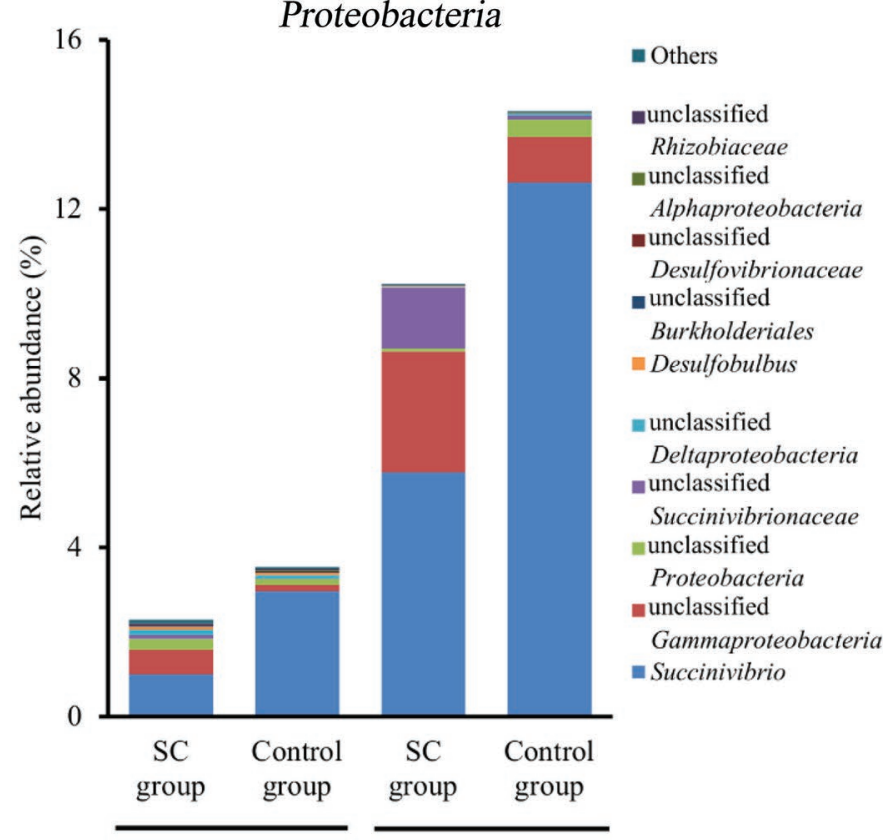

Day 0 n Others

- Butyricimonas

- Bacteroides

- Alistipes

- Porphyromonas

Paraprevotella

- unclassified

Marinilabiliaceae

nunclassified

Prevotellaceae

nunclassified

Bacteroidetes

nunclassified

Bacteroidales

- Prevotella

Figure 3. Relative abundance profiles of 4 major bacterial phyla and genera in Holstein calves administered $0 \mathrm{~g}($ control group, $\mathrm{n}=5)$ or $2 \mathrm{~g}$ (SC group, $\mathrm{n}=5$ ) of active dried Saccharomyces cerevisiae twice daily. Days 0 and 3 denote samples taken $1 \mathrm{~d}$ before and $1 \mathrm{~d}$ after the ruminal acidosis challenge, respectively. The ruminal acidosis challenge was performed on d 1 and 2. Data are shown as percentages of the total identified sequences per group. 
However, most previous studies on the ruminal acidosis challenge, yeast supplementation, and bacterial community have focused on adult cattle, not calves. Therefore, the slight discrepancy between the cited literature and the present study may arise from immature rumen fermentation and bacterial community in calves after weaning.

In the present study, significant depression of 24-h and 1-h mean ruminal $\mathrm{pH}$ was observed simultaneously with increases in the duration of time when $\mathrm{pH}$ was under 5.6 and the area under $\mathrm{pH} 5.6$ in both groups. However, the results of ruminal acidosis were more severe in the SC group, consistent with the numerically higher total VFA concentration and significantly greater lactic acid concentration and proportion of butyric acid in that group. In lactating dairy cows, ADSC supplementation showed mitigated effects of SARA $(122 \pm 57$ vs. $321 \pm 53 \mathrm{~min} / \mathrm{d}$ at $\mathrm{pH}<5.6)$ and increased total VFA, propionate, butyrate, valerate, and isovalerate and reduced acetate concentrations $(\mathrm{m} M)$ at the end of a long-term HG feeding (3 wk) compared with control cows (AlZahal et al., 2014). In contrast to studies of adult cattle, Xiao et al. (2016) reported that S. cerevisiae fermentation products were associated with significantly higher butyrate and numerically higher total VFA concentrations in preweaning dairy calves. There were differences among the yeast supplementation type used, the dietary composition, and the age of animals between the present study and previous works (Thrune et al., 2009; AlZahal et al., 2014; Xiao et al., 2016); nonetheless, the rumen fermentation characteristics in the present study were more consistent with data on preweaning calves (Xiao et al., 2016) than data on adult cattle (Thrune et al., 2009; AlZahal et al., 2014). Moreover, diurnal changes in the 1-h mean ruminal $\mathrm{pH}$ (an important regulation factor for ruminal $\mathrm{pH}$; Kim et al., 2016) were identified in both groups, and no effects on health condition or blood enzyme activities (aspartate transaminase and $\gamma$-glutamyl transpeptidase) were observed during the prechallenge, ruminal acidosis, and postchallenge periods. These results suggest that calves that received ADSC produce more butyric and lactic acids as energy sources. In other words, ADSC supplementation in calves promotes the production of energy sources (butyric and lactic acids) with no effects on their heath condition despite an abrupt change in diet composition from HF to HG during the short-term ruminal acidosis challenge. Consequently, our results suggest a possible benefit of ADSC in the rumen fermentation in growing calves or cattle, as reported previously (Lesmeister et al., 2004). However, the crossover design may not be the best for such studies with growing animals, and a carryover effect was observed in the proportion of butyric acid in the present study,

Table 5. Relative abundances of major bacterial phyla and genera in Holstein calves administered $0 \mathrm{~g}$ (control group; $\mathrm{n}=5$ ) or $2 \mathrm{~g}$ (SC group; $\mathrm{n}=5$ ) of active dried Saccharomyces cerevisiae twice daily

\begin{tabular}{|c|c|c|c|c|c|}
\hline \multirow[b]{2}{*}{ Item } & \multicolumn{2}{|c|}{ Control } & \multicolumn{2}{|c|}{$\mathrm{SC}$} & \multirow[b]{2}{*}{ SEM } \\
\hline & d $0^{1}$ & d 3 & d 0 & d 3 & \\
\hline \multicolumn{6}{|l|}{ Bacterial phylum } \\
\hline Firmicutes & 51.8 & $32.7^{\mathrm{a}}$ & 55.1 & $25.1^{\mathrm{a}}$ & 0.01 \\
\hline Bacteroidetes & 34.1 & $39.7^{\mathrm{A}}$ & 35.8 & 22.0 & 0.02 \\
\hline Actinobacteria & 0.9 & $10.0^{\mathrm{a}, \mathrm{B}}$ & 0.5 & $41.8^{\mathrm{a}}$ & 0.04 \\
\hline Proteobacteria & 3.5 & $14.3^{\mathrm{a}}$ & 2.3 & $10.2^{\mathrm{A}}$ & 0.02 \\
\hline \multicolumn{6}{|l|}{ Bacterial genus } \\
\hline Prevotella & 15.2 & $29.8^{\mathrm{ab}}$ & 14.0 & 14.7 & 0.04 \\
\hline Unclassified Ruminococcaceae & 15.2 & $7.8^{\mathrm{B}}$ & 16.2 & $1.5^{\mathrm{a}}$ & 0.01 \\
\hline Unclassified Lachnospiraceae & $10.7^{\mathrm{b}}$ & $5.2^{\mathrm{a}}$ & 15.1 & $3.3^{\mathrm{a}}$ & 0.01 \\
\hline Bifidobacterium & 0.5 & $9.1^{\mathrm{a}, \mathrm{B}}$ & 0.1 & $40.1^{\mathrm{a}}$ & 0.09 \\
\hline Unclassified Bacteroidales & $7.3^{\mathrm{B}}$ & $3.9^{\mathrm{A}}$ & 11.0 & 3.4 & 0.01 \\
\hline Succinivibrio & 3.0 & 12.6 & 1.0 & 5.8 & 0.02 \\
\hline Unclassified Clostridiales & 9.1 & $4.2^{\mathrm{A}, \mathrm{b}}$ & 8.6 & $1.1^{\mathrm{a}}$ & 0.00 \\
\hline Unclassified Bacteroidetes & 6.2 & $2.9^{\mathrm{A}}$ & 6.2 & $1.9^{\mathrm{a}}$ & 0.01 \\
\hline Kandleria & 2.5 & $2.3^{\mathrm{B}}$ & 3.2 & 8.9 & 0.03 \\
\hline Unclassified Prevotellaceae & 5.4 & $3.1^{\mathrm{a}}$ & $4.5^{\mathrm{A}}$ & 2.1 & 0.01 \\
\hline Sharpea & 1.5 & 6.2 & 0.8 & 7.3 & 0.02 \\
\hline Ruminococcus & 3.7 & $0.2^{\mathrm{ab}}$ & 3.4 & $0.0^{\mathrm{a}}$ & 0.01 \\
\hline Pseudobutyrivibrio & 2.0 & $0.6^{\mathrm{a}}$ & 2.5 & $0.1^{\mathrm{a}}$ & 0.01 \\
\hline Succiniclasticum & 1.1 & 1.2 & 1.0 & 0.7 & 0.01 \\
\hline
\end{tabular}


WATANABE ET AL.

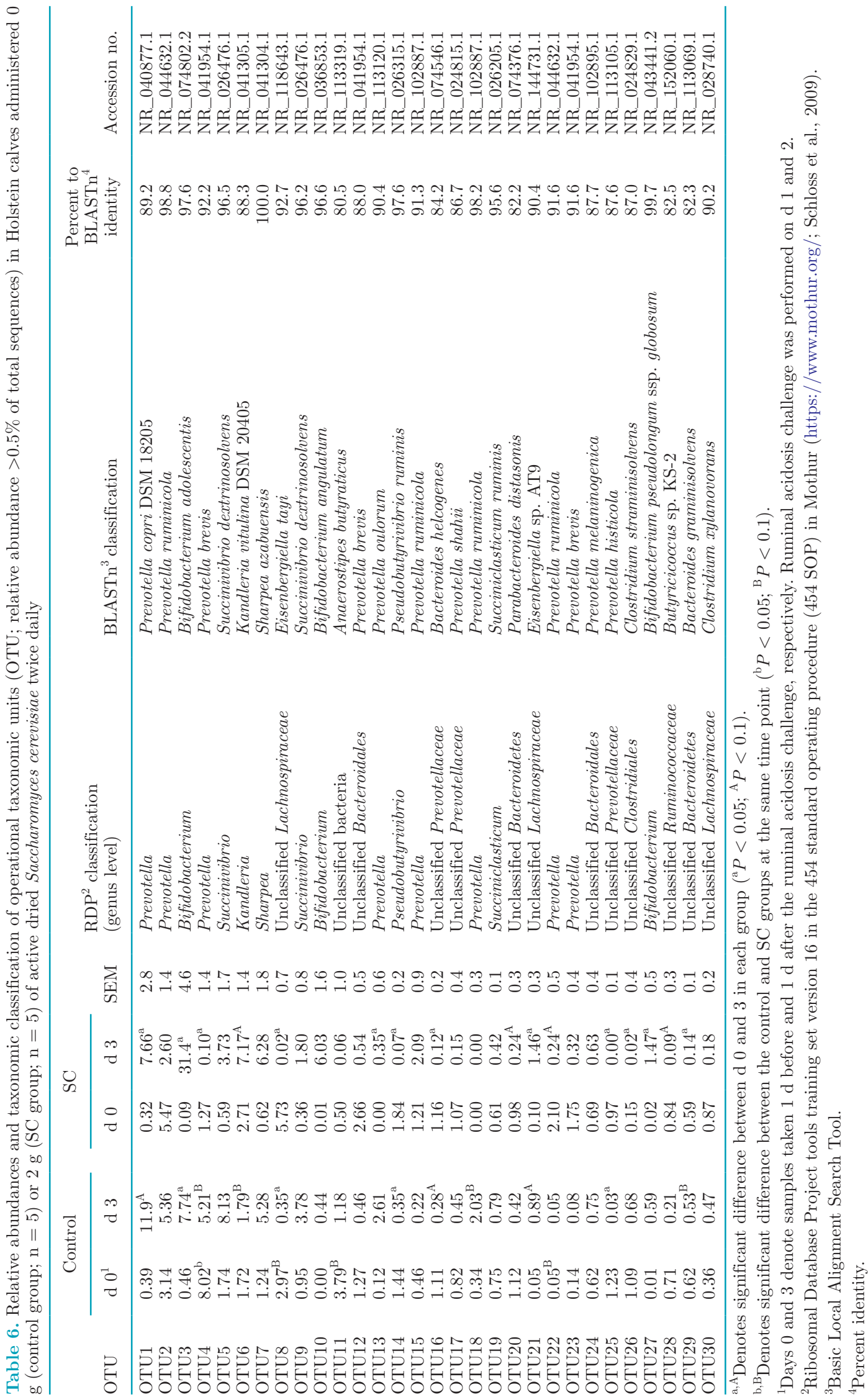


suggesting an insufficient wash-out period or preadaptation period to ADSC. Therefore, the proportion of butyric acid and its correlations with OTU should be interpreted with caution, and further studies are necessary to exclude experimental design problems and to identify the long-term effects of ADSC supplementation on growth performance.

In the present study, we only analyzed the rumen fluid bacterial community, which may be insufficient to elucidate all the effects of ADSC supplementation. Therefore, it is required to consider the bacterial community with ruminal $\mathrm{pH}$ and fermentation characteristics. In accordance with changes in ruminal $\mathrm{pH}$, rumen bacterial diversity and community composition were also influenced by the short-term ruminal acidosis challenge despite the lack of apparent separation between the 2 groups in PCoA plots. Several studies have shown that low ruminal $\mathrm{pH}$ due to an HG diet causes a decrease in rumen fluid bacterial diversity (Huo et al., 2014; Kim et al., 2016). In the present study, the depression of ruminal $\mathrm{pH}$ induced a significant decline in bacterial diversity in both groups during the ruminal acidosis challenge, which was more severe in the SC group, mirroring the pattern of decline in ruminal $\mathrm{pH}$. Thus, the ruminal acidosis challenge has a significant influence on rumen bacterial diversity in both groups, and the SC group in our study might have been more severely affected by the ruminal acidosis challenge compared with the control group due to the severe depression of ruminal $\mathrm{pH}$ observed.

Among the dominant bacterial phyla, Firmicutes and Bacteroidetes were the most abundant in the present study, followed by Actinobacteria and Proteobacteria. In the previous studies, it was demonstrated that a low ruminal $\mathrm{pH}$ induced a decrease not only in bacterial diversity but also in the proportion of Bacteroidetes due to death or lysis of gram-negative bacteria caused by high acidity coinciding with an increase in the proportion of Firmicutes (Nagaraja and Titgemeyer, 2007; Mao et al., 2013; Huo et al., 2014). However, these changes were not consistent with the present study, and the genera Bifidobacterium and Succinivibrio and their phyla (Actinobacteria and Proteobacteria, respectively) showed noticeable increases during the ruminal acido-

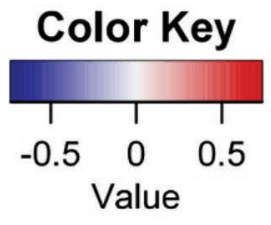

OTU Genus

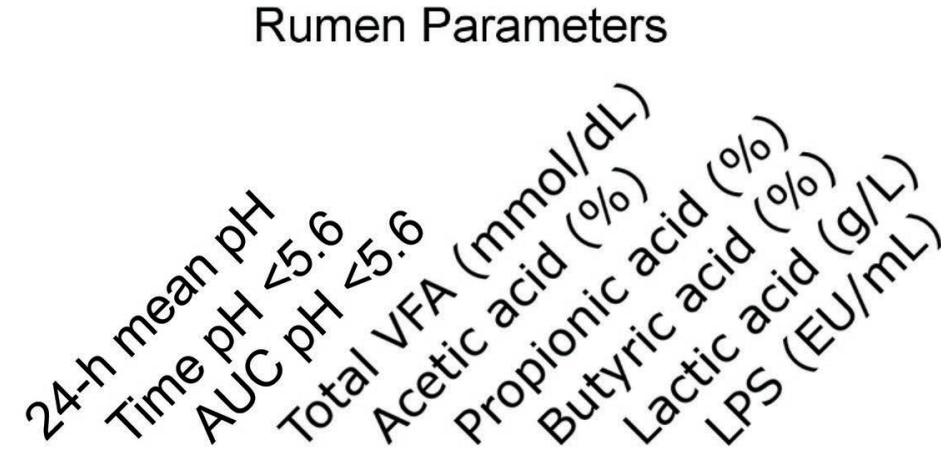

OTU1 Prevotella

OTU3 Bifidobacterium

OTU5 Succinivibrio

OTU6 Kandleria

OTU8 Unclassified Lachnospiraceae

OTU9 Succinivibrio

OTU14 Pseudobutyrivibrio

OTU15 Prevotella

OTU16 Unclassified Prevotellaceae

OTU18 Prevotella

OTU25 Unclassified Prevotellaceae

OTU27 Bifidobacterium

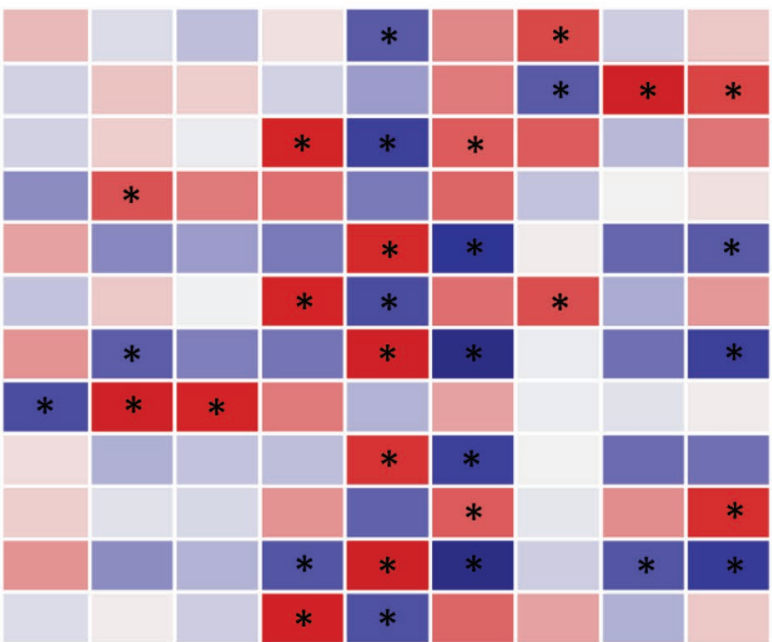

Figure 4. Correlation analyses between the relative abundances of operational taxonomic units (OTU; relative abundance $>0.5 \%$ of total sequences) and rumen parameters. Cells are colored based on Pearson correlation coefficient analyses. Blue represents a negative correlation, and red represents a positive correlation. ${ }^{*}$ Significant correlation $(P<0.05)$ between rumen parameters and OTU. 24-h mean pH $=24-\mathrm{h}$ mean ruminal $\mathrm{pH}$; Time $\mathrm{pH}<5.6=$ duration of time when $\mathrm{pH}$ was $<5.6$; AUC $\mathrm{pH}<5.6=$ area under $\mathrm{pH}<5.6$. 
sis challenge. It may be because we performed a very short-term ruminal acidosis challenge ( $2 \mathrm{~d}$ of HG feeding), which may not have allowed enough time for some bacteria to turn over. Furthermore, Prevotella was the most abundant bacterial genus in the present study due to its capacity to use a variety of substrates (Jami and Mizrahi, 2012; Golder et al., 2014; Kim et al., 2016).

Xiao et al. (2016) reported that $S$. cerevisiae fermentation products increased Butyrivibrio and decreased Prevotella richness in the rumen fluid, and these genera resulted in increased butyrate production in preweaning dairy calves. A positive correlation was identified between butyric acid proportion and some OTU, including OTU1 (Prevotella) and OTU9 (Succinivibrio), based on Pearson correlation analyses. Prevotella species are considered succinate producers from various substrates (Purushe et al., 2010), and Succinivibrio species play ecologically important roles as non-fibrolytic starch digesters, producing acetic and succinic acids from soluble carbohydrates in the rumen (Hippe et al., 1999; Koike et al., 2007) despite significant correlations between butyrate and these bacteria. Therefore, we can only assume that the proportion of these bacteria increased due to an increase in available substrates for their growth (Kim et al., 2016; Neubauer et al., 2018). However, we could not provide a plausible reason for the accelerated increase in the relative abundances of Bifidobacterium species in the SC group, and thus further studies are needed to elucidate the relationship between ADSC supplementation and the growth of Bifidobacterium species during the ruminal acidosis challenge in Holstein calves.

In the present study, qPCR was performed using several bacterial plasmids for validation, and the direction of the changes in relative abundance was consistent in the 454 pyrosequencing and qPCR analyses. Interestingly, the relative abundances of the genus Bifidobacterium and OTU3 (Bifidobacterium) increased dramatically in the SC group (0.1 to $42.0 \%$ and 0.1 to $31.4 \%$, respectively) during the ruminal acidosis challenge, and the lactic acid concentration was positively correlated with OTU3 (Bifidobacterium). In general, Bifidobacterium species utilize fructose, galactose, glucose, and starch as substrates to produce lactate and acetate (Amaretti et al., 2007; Mao et al., 2013), and the growth of Bifidobacterium species in this study was consistent with previous studies showing that the number of Bifidobacterium species increased with an increasing proportion of grain in the diet (Trovatelli and Matteuzzi, 1976; Mao et al., 2013). Meanwhile, human gut studies have noted that cross-feeding between Bifidobacterium adolescentis and butyrate-producing anaerobes stimulates butyrate formation due to consumption of fermentation end products such as lactate and acetate (Belenguer et al., 2006; Rios-Covian et al., 2015). These results suggest that increased proportion of Bifidobacterium species might have stimulated the butyrate production in the present study. Collectively, these data indicate that ADSC supplementation enhanced the growth of Bifidobacterium species and increased ruminal proportion of butyric acid and peripheral BHB concentration during the ruminal acidosis challenge in Holstein calves after weaning.

\section{CONCLUSIONS}

Supplementation with ADSC induced higher levels of butyric and lactic acids during the ruminal acidosis challenge, resulting in intense depression of ruminal $\mathrm{pH}$ (more severe ruminal acidosis) and bacterial diversity. Calves that received ADSC showed increased relative abundances of Bifidobacterium species during the ruminal acidosis challenge. These bacteria produce a higher lactic acid concentration and might stimulate butyrate production in the SC group in the rumen. However, the mechanisms of these effects remain unclear, and the effects on calf growth could not be assessed due to the short-term nature of this experiment. Therefore, further studies are needed to clarify the long-term relationships among ADSC supplementation, growth of Bifidobacterium species, and growth performance of Holstein calves after weaning.

\section{ACKNOWLEDGMENTS}

The authors thank Yasuo Kobayashi (Research Faculty of Agriculture, Hokkaido University, Hokkaido, Japan), who kindly provided the recombinant plasmid DNA for quantitative real-time PCR analysis. This work was supported by the Cabinet Office, Government of Japan, Cross-Ministerial Strategic Innovation Promotion Program (SIP) "Technologies for Creating Next-Generation Agriculture, Forestry and Fisheries."

\section{REFERENCES}

AlZahal, O., L. Dionissopoulos, A. H. Laarman, N. Walker, and B. W McBride. 2014. Active dry Saccharomyces cerevisiae can alleviate the effect of subacute ruminal acidosis in lactating dairy cows. J. Dairy Sci. 97:7751-7763.

Amaretti, A., T. Bernardi, E. Tamburini, S. Zanoni, M. Lomma, D. Matteuzzi, and M. Rossi. 2007. Kinetics and metabolism of Bifidobacterium adolescentis MB 239 growing on glucose, galactose, lactose, and galactooligosaccharides. Appl. Environ. Microbiol. 73:3637-3644.

Belenguer, A., S. H. Duncan, A. G. Calder, G. Holtrop, P. Louis, G. E. Lobley, and H. J. Flint. 2006. Two routes of metabolic crossfeeding between Bifidobacterium adolescentis and butyrate-producing anaerobes from the human gut. Appl. Environ. Microbiol. 72:3593-3599. 
Chaucheyras-Durand, F., N. D. Walker, and A. Bach. 2008. Effects of active dry yeasts on the rumen microbial ecosystem: Past, present and future. Anim. Feed Sci. Technol. 145:5-26.

Fomenky, B. E., D. N. Do, G. Talbot, J. Chiquette, N. Bissonnette, Y. P. Chouinard, M. Lessard, and E. M. Ibeagha-Awemu. 2018. Direct-fed microbial supplementation influences the bacteria community composition of the gastrointestinal tract of pre-and postweaned calves. Sci. Rep. 8:14147.

Golder, H. M., S. E. Denman, C. McSweeney, P. Celi, and I. J. Lean. 2014. Ruminal bacterial community shifts in grain-, sugar-, and histidine-challenged dairy heifers. J. Dairy Sci. 97:5131-5150.

Hippe, H., A. Hagelstein, I. Kramer, J. Swiderski, and E. Stackebrandt. 1999. Phylogenetic analysis of Formivibrio citricus, Propionivibrio dicarboxylicus, Anaerobiospirillum thomasii, Succinimonas amylolytica and Succinivibrio dextrinosolvens and proposal of Succinivibrionaceae fam. nov. Int. J. Syst. Bacteriol. 49:779-782.

Hirabayashi, H., K. Kawashima, T. Okimura, A. Tateno, A. Suzuki, S. Asakuma, N. Isobe, T. Obitsu, S. Kushibiki, and T. Sugino. 2017. Effect of nutrient levels during the far-off period on postpartum productivity in dairy cows. Anim. Sci. J. 88:1162-1170.

Hook, S. E., M. A. Steele, K. S. Northwood, J. Dijkstra, J. France, A. D. G. Wright, and B. W. McBride. 2011. Impact of subacute ruminal acidosis (SARA) adaptation and recovery on the density and diversity of bacteria in the rumen of dairy cows. FEMS Microbiol. Ecol. 78:275-284.

Huo, W., W. Zhu, and S. Mao. 2014. Impact of subacute ruminal acidosis on the diversity of liquid and solid-associated bacteria in the rumen of goats. World J. Microbiol. Biotechnol. 30:669-680.

Jami, E., A. Israel, A. Kotser, and I. Mizrahi. 2013. Exploring the bovine rumen bacterial community from birth to adulthood. ISME J. $7: 1069-1079$.

Jami, E., and I. Mizrahi. 2012. Composition and similarity of bovine rumen microbiota across individual animals. PLoS One 7:e33306.

Khafipour, E., D. O. Krause, and J. C. Plaizier. 2009. A grain-based subacute ruminal acidosis challenge causes translocation of lipopolysaccharide and triggers inflammation. J. Dairy Sci. 92:10601070.

Kim, S. W., W. Suda, S. Kim, K. Oshima, S. Fukuda, H. Ohno, H. Morita, and M. Hattori. 2013. Robustness of gut microbiota of healthy adults in response to probiotic intervention revealed by high-throughput pyrosequencing. DNA Res. 20:241-253.

Kim, Y.-H., R. Nagata, N. Ohtani, T. Ichijo, K. Ikuta, and S. Sato. 2016. Effects of dietary forage and calf starter diet on ruminal $\mathrm{pH}$ and bacteria in Holstein calves during weaning transition. Front. Microbiol. 7:1575.

Koike, S., H. Yabuki, and Y. Kobayashi. 2007. Validation and application of real-time polymerase chain reaction assays for representative rumen bacteria. Anim. Sci. J. 78:135-141.

Lesmeister, K. E., A. J. Heinrichs, and M. T. Gabler. 2004. Effects of supplemental yeast (Saccharomyces cerevisiae) culture on rumen development, growth characteristics, and blood parameters in neonatal dairy calves. J. Dairy Sci. 87:1832-1839.

Li, S., E. Khafipour, D. O. Krause, A. Kroeker, J. C. RodriguezLecompte, G. N. Gozho, and J. C. Plaizier. 2012. Effects of subacute ruminal acidosis challenges on fermentation and endotoxins in the rumen and hindgut of dairy cows. J. Dairy Sci. 95:294-303.

Lozupone, C., and R. Knight. 2005. UniFrac: A new phylogenetic method for comparing microbial communities. Appl. Environ. Microbiol. 71:8228-8235.

Mao, S. Y., R. Y. Zhang, D. S. Wang, and W. Y. Zhu. 2013. Impact of subacute ruminal acidosis (SARA) adaptation on rumen microbiota in dairy cattle using pyrosequencing. Anaerobe 24:12-19.
Nagaraja, T. G., and E. C. Titgemeyer. 2007. Ruminal acidosis in beef cattle: The current microbiological and nutritional outlook. J. Dairy Sci. 90(Suppl. 1):E17-E38.

Neubauer, V., R. Petri, E. Humer, I. Kröger, E. Mann, N. Reisinger, M. Wagner, and Q. Zebeli. 2018. High-grain diets supplemented with phytogenic compounds or autolyzed yeast modulate ruminal bacterial community and fermentation in dry cows. J. Dairy Sci. 101:2335-2349.

Petri, R. M., T. Schwaiger, G. B. Penner, K. A. Beauchemin, R. J. Forster, J. J. McKinnon, and T. A. McAllister. 2013. Characterization of the core rumen microbiome in cattle during transition from forage to concentrate as well as during and after an acidotic challenge. PLoS One 8:e83424.

Plaizier, J. C., D. O. Krause, G. N. Gozho, and B. W. McBride. 2008. Subacute ruminal acidosis in dairy cows: The physiological causes, incidence and consequences. Vet. J. 176:21-31.

Pruesse, E., C. Quast, K. Knittel, B. M. Fuchs, W. Ludwig, J. Peplies, and F. O. Glöckner. 2007. SILVA: A comprehensive online resource for quality checked and aligned ribosomal RNA sequence data compatible with ARB. Nucleic Acids Res. 35:7188-7196.

Purushe, J., D. E. Fouts, M. Morrison, B. A. White, R. I. Mackie, North American Consortium for Rumen Bacteria, P. M. Coutinho, B. Henrissat, and K. E. Nelson. 2010. Comparative genome analysis of Prevotella ruminicola and Prevotella bryantii: Insights into their environmental niche. Microb. Ecol. 60:721-729.

Rios-Covian, D., M. Gueimonde, S. H. Duncan, H. J. Flint, and C. G. de Los Reyes-Gavilan. 2015. Enhanced butyrate formation by cross-feeding between Faecalibacterium prausnitzii and Bifidobacterium adolescentis. FEMS Microbiol. Lett. 362:fnv176.

Sato, S., H. Mizuguchi, K. Ito, K. Ikuta, A. Kimura, and K. Okada. 2012. Technical note: Development and testing of a radio transmission $\mathrm{pH}$ measurement system for continuous monitoring of ruminal $\mathrm{pH}$ in cows. Prev. Vet. Med. 103:274-279.

Schloss, P. D., D. Gevers, and S. L. Westcott. 2011. Reducing the effects of PCR amplification and sequencing artifacts on 16S rRNA based studies. PLoS One 6:e27310.

Schloss, P. D., S. L. Westcott, T. Ryabin, J. R. Hall, M. Hartmann, E. B. Hollister, A. L. Ryan, B. O. Brian, H. P. Donovan, J. R. Courtney, W. S. Jason, S. Blaz, G. T. Gerhard, J. V. H. David, and F. W. Carolyn. 2009. Introducing mothur: Open-source, platform-independent, community-supported software for describing and comparing microbial communities. Appl. Environ. Microbiol. 75:7537-7541.

Thrune, M., A. Bach, M. Ruiz-Moreno, M. D. Stern, and J. G. Linn. 2009. Effects of Saccharomyces cerevisiae on ruminal $\mathrm{pH}$ and microbial fermentation in dairy cows: Yeast supplementation on rumen fermentation. Livest. Sci. 124:261-265.

Trovatelli, L. D., and D. Matteuzzi. 1976. Presence of bifidobacteria in the rumen of calves fed different rations. Appl. Environ. Microbiol. $32: 470-473$.

Vyas, D., A. Uwizeye, R. Mohammed, W. Z. Yang, N. D. Walker, and K. A. Beauchemin. 2014. The effects of active dried and killed dried yeast on subacute ruminal acidosis, ruminal fermentation, and nutrient digestibility in beef heifers. J. Anim. Sci. 92:724-732.

Xiao, J. X., G. M. Alugongo, R. Chung, S. Z. Dong, S. L. Li, I. Yoon, Z. H. Wu, and Z. J. Cao. 2016. Effects of Saccharomyces cerevisiae fermentation products on dairy calves: Ruminal fermentation, gastrointestinal morphology, and microbial community. J. Dairy Sci. 99:5401-5412 